\title{
Enactive becoming
}

\section{Ezequiel A. Di Paolo ${ }^{1,2,3}$ (D)}

Published online: 11 January 2020

(C) The Author(s) 2020

\begin{abstract}
The enactive approach provides a perspective on human bodies in their organic, sensorimotor, social, and linguistic dimensions, but many fundamental issues still remain unaddressed. A crucial desideratum for a theory of human bodies is that it be able to account for concrete human becoming. In this article I show that enactive theory possesses resources to achieve this goal. Being an existential structure, human becoming is best approached by a series of progressive formal indications. I discuss three standpoints on human becoming as open, indeterminate, and therefore historical using the voices of Pico della Mirandola, Gordon W. Allport, and Paulo Freire. Drawing on Gilbert Simondon's philosophy of individuation we move from an existential to an ontological register in looking at modes of embodied becoming. His scheme of interpretation of the relation between modes of individuation allows us to understand human becoming in terms of a tendency to neotenization. I compare this ontology with an enactive theoretical account of the dimensions of embodiment, finding several compatibilities and complementarities. Various forms of bodily unfinishedness in enaction fit the Simondonian ontology and the existential analysis, where transindividuality corresponds to participatory sense-making and Freire's joint becoming of individuals and communities correlates with the open tensions in linguistic bodies between incorporation and incarnation of linguistic acts. I test some of this ideas by considering the plausibility of artificial bodies and personal becoming from an enactive perspective, using the case of replicants in the film Blade Runner. The conclusion is that any kind of personhood, replicants included, requires living through an actual history of concrete becoming.
\end{abstract}

Keywords Human becoming · Enaction · Gilbert Simondon · Individuality · Communities · Replicants

Ezequiel A. Di Paolo

ezequiel.dipaolo@ehu.es

1 Ikerbasque - Basque Foundation for Science, Bilbao, Spain

2 IAS-Research, University of the Basque Country (UPV/EHU), San Sebastián, Spain

3 Centre for Computational Neuroscience and Robotics, University of Sussex, Brighton, UK 


\section{Introduction}

It is curious that, with all the currently active schools of embodied cognitive science, there has not been much direct concern with the question of how we should think about bodies. There are a few exceptions, notably the branch of enactive thinking originated by Francisco Varela, in which the issue of bodily selfindividuation plays a key role in the naturalization of the mind. ${ }^{1}$ The same enactive school is also nourished by phenomenological traditions from which we learn about bodies as bearers of situated powers and sensitivities, unlike other objects in the world. But apart from this, and even within enactivist research, we tend to treat bodies more or less as givens, as starting points, and as constraints to developing ideas (they should make bodily sense). Little is done in the way of raising questions concerning how bodies are constituted, what makes them bodies. Often, no more than a nod is given towards narratives of active self-individuation, metabolism, relationality, bodies as processes not machines, etc. But this still fits a broad range of possibilities. Should we go along with the traditional picture and think of bodies mainly from an organic, anatomical, physiological perspective (the way they look laid down on the operating table)? Should we see them as constituted by their practices, their history, their way of life, their choices, their socio-environmental relations (and I really mean constituted as in made, assembled, put together, by these processes)?

The second possibility has been explored in recent enactivist work (Di Paolo et al. 2017; Di Paolo et al. 2018). The idea is to look beyond the organic constitution of biological bodies (autopoiesis) but keeping within the logic of individuation, i.e., precarious autonomous processes of material and relational constitution taking place not only in the domain of biochemical reactions but also in the organization of sensorimotor patterns (sensorimotor bodies) and socio-linguistic agencies (linguistic bodies). The organic dimension of bodies does not disappear or fade into a background when considering other forms of bodily self-constitution. On the contrary, according to the enactive view, the different dimensions form an entangled stream of processes at multiple scales, an ongoing becoming whose structure is not exhausted by the cycles of metabolism or the path-dependent nature of development. These enactive proposals converge with recent work on environmental epigenetics that shows that habits and sociomaterial stresses become molecularly embodied and affect gene expression (Landecker and Panofsky 2013). They converge also with ethnographic studies such as those by Mol and Law (2004) who describe the multiplicity of choices and tradeoffs that constitute human embodiment as an unremitting task, a series of enactments, rather than the given, unchanging background to our activities. Similar considerations, whereby bodies constitute and are in turn constituted in exchanges with the world, are found in philosophers such as Suzanne Langer (1967) and Christine Korsgaard (2009).

\footnotetext{
${ }^{1}$ See discussions on biological, sensorimotor, and linguistic self-individuation (Varela 1997; Weber and Varela 2002; Di Paolo 2005; Thompson 2007; Di Paolo et al. 2017, 2018). Other exceptions come from ecological psychology, e.g., the work of Mark Latash (2008) on body synergies and Michael Turvey (2007) and colleagues on tensegrity in the organization of the musculoskeletal system.
} 
What distinguishes these perspectives from other work in embodied cognitive science is that the two-way enabling relations between bodies and particular explanatory targets (perception, social cognition, etc.) is not only acknowledged but becomes itself an explanatory target. In other words, bodies become explananda when their relations to the world and their activities are revealed to be constitutive of the processes of bodily becoming.

This is an evolving picture, far from complete. One piece that is missing is a more detailed look at the existential structure of becoming in conjunction with an operational/theoretical description of its relevant processes. How can we progressively hint at the structure of becoming beyond merely acknowledging the incessant change of metabolism and the processual nature of sensorimotor and linguistic development? How can this exercise serve to clarify or extend enactive theory?

My purpose here is to establish indications of human becoming as an existential structure of human bodies and to relate these indications to an ontology of individuation and a theoretical framework that can articulate it scientifically.

As becoming is an existential structure of being human, one that paradoxically affirms and puts into question the fixity of human bodies, it is not advisable to proceed by defining this structure a priori. This only forecloses any exploration into the assumptions that go into such finished definitions. We must proceed by a series of formal indications, hints, signs (formale Anzeige) that, as in the early Heideggerian tradition (Heidegger 2001), serve the purpose of orienting the reader to phenomenological and existential insights she must herself perform so as to give flesh to an existential concept and be able to ascertain the suitability of the theoretical proposals that follow. Indications, unlike settled definitions, possess not only a referential character but a deterring one, functioning both as guides and as calls to hold off the habitual ways in which we have come to understand the ideas they indicate (ibid. p. 105). The point is to avoid adopting a theorizing attitude too early in the process (eventually that is where we wish to go) and run the risk of freezing concepts at too abstract a stage. As Denis McManus (2013) puts it, formal indications act as provocations to "look and see" for ourselves, prior to any theorizing.

Following this method, we approach the idea of human becoming through the voices of three otherwise rather different thinkers: Pico della Mirandola, Gordon W. Allport, and Paulo Freire. In general, their ideas are compatible with, though far from identical to, the views of other thinkers regularly appearing in the "enactive canon" such as Hans Jonas, Maurice Merleau-Ponty, philosophical anthropologists like Helmuth Plessner, and pragmatists like John Dewey. Examining these compatibilities and differences remains beyond the scope of the present discussion where our aim is for their voices to provide us with increasingly articulated indications of human becoming. After this, I will briefly discuss Gilbert Simondon's ontology of individuation, and in particular his remarks on neotenization. This will serve two purposes: 1) to highlight human becoming as part of a tendency towards socially mediated forms of potentiality, and 2) to bridge this insight with the theoretical apparatus of enactive theory. The three central sections thus form one iteration of an epistemic arc: existential analysis, ontology, theoretical articulation. To put some of these ideas to the test, I will offer in the final section some reflections, using the film Blade Runner, on the plausibility of artificial human becoming. 


\section{Indications of human becoming: Pico, Allport, Freire}

Pico della Mirandola composed his Oration on the Dignity of Man probably in 1486. In seeking what is admirable about human beings, ${ }^{2}$ and dissatisfied with answers that point to reason, discernment, the acuteness of the senses, and so on, Pico saw something more fundamental about the nature of humans. This nature is indeterminate. Says God to Adam: "Neither a fixed abode nor a form that is thine alone nor any function peculiar to thyself have we given thee, Adam, to the end that according to thy longing and according to thy judgment thou mayest have and possess what abode, what form, and what functions thou thyself shalt desire" (della Mirandola 1948, p. 224). Such indeterminacy contrasts with the nature of other beings, beasts that "as soon as they are born ... bring with them from their mother's womb all they will ever possess" and spiritual beings, whose becoming, if it once existed, is negligible in comparison with their eternity. These natures are fixed. Humans by comparison are subject to no prescribed limits other than those they set themselves. This gives them "the power to degenerate into the lower forms of life, which are brutish ... [and the power] to be reborn into the higher forms, which are divine" (p. 225).

Today the voluntaristic accent of the Oration cast doubts on Pico's vision (Can we really choose our nature as easily as adjusting a set of dials?). The images of powers and potentialities are, however, still pertinent and indicate one key aspect of the structure of becoming. Humans are born with "the seeds of all kinds and the germs of every way of life"; those we cultivate will grow and bear fruit. There is here a theme of development, temporality, and historicity as the dialectical counterpart of indeterminacy. Our nature is indeterminate, but it does not remain so once we move in the world, make our choices, confront our surroundings. The implication is that we transit from states of high potentiality to un-prescribed states of determination. In sum,

Human becoming: indeterminate nature; a history of passages from original states of potentiality mediated by powers and cultivation.

Adding specificity to the indications of indeterminateness and historicity, we may compare Pico's with other views that share a critical stance toward attempts to prescribe human nature as a set of pregiven determinations.

In his book Becoming: Basic Considerations for a Psychology of Personality, Gordon W. Allport articulates a view of human becoming that still informs contemporary psychology. "Personality is less a finished product than a transitive process. While it has some stable features, it is at the same time continually undergoing change"

\footnotetext{
${ }^{2}$ Here and in other cases in this article I am extending to all human beings what has been predicated specifically about man. This, I hope, may be acceptable for my purpose, which is to draw a space of ideas about human becoming. In a different sort of inquiry, however, it will not be entirely correct to assume these views were necessarily also held by the authors and contemporaries about all humans, including women, people with disabilities, non-European people, slaves, etc.

${ }^{3}$ Becoming is a key notion in process-oriented and relational approaches in developmental psychology, where concern is less with proposing universal stages of cognitive and social development and more with understanding how various processes (genetic, physiological, behavioural, social, environmental) intertwine and create multiple viable "developmental paths" moving across webs of historical possibilities, (see, e.g., Adolph and Hoch 2019; Overton 2015; Stetsenko 2017; Witherington et al. 2018).
} 
(Allport 1955, p. 19). Allport refers to this process as becoming or individuation. Unlike plants and animals, human beings do not live by repeating with trivial variation the pattern of the species: "personality is governed not only by the impact [of the environment on the organism] ... Its process of becoming is governed, as well, by a disposition to realize its possibilities, i.e., to become characteristically human at all stages of development" (p. 27). Becoming is the formation of an individual style.

Unlike other lifeforms, human motivation is characterized by strivings that go beyond the reduction of tensions. Longer range goals differentiate humans from animals. Take Roald Amundsen, whose life from the age of 15 was passionately motivated by the idea of becoming a polar explorer. Allport does not discuss what makes such motivation and commitment possible, and he may be biased toward particular norms that applaud relentless persistence in pursuit of meaningful goals. But it seems true that, while we do not all become polar explorers, we entertain and work toward longer term goals that take us out of our comfort zones. With the same caveats, we may follow Allport in his assertion that what lies at the core of personality is an active kind of growth whose goals are unattainable (or challenging and expanding, we could qualify). The unity that is conferred to personality is not a unity of fulfillment or reduced tension. Motives for growth "maintain tension in the interest of distant and often unattainable goals", distinguishing "human from animal becoming and adult from infant becoming" (p. 68). There is no tension reduction, but tension creation, with each success only raising the bar for new aspirations.

In contrast to Pico, for Allport it is not a question of resolving an indeterminacy present at birth, but a question of continuously striving for open and challenging goals that confer unity in the tensions they create, in the activities they engender. Human becoming, in other words, is characterized by a sustained or renewed potentiality in adult life and not only in a multiplicity of options during childhood. History is not simply a series of accumulated determinations, but the result of active and projective orientations towards renewed potentialities, enacted in the form of work, training, trade-offs, etc. In sum,

Human becoming: indeterminate nature; potentialities not (all) predetermined but created and renewed throughout a lifetime via strivings for longer-term goals; history mediated by choice and effort giving unity to an individual style.

Socialization is an enabling condition for learning to entertain longer-term goals. But while Allport discusses socialization at length, he does not think it goes beyond providing the child with enough groundwork so as to arrive at a stage where he or she is "free to become" (p. 33). Allport considers as an equally if not more important condition the child's own demands for autonomy and self-assertion, urges he implicitly deems individual rather than social in origin. He talks about two modes of becoming, "the tribal and the personal: the one that makes [the child] into a mirror, the other that lights the lamp of individuality within" (p. 35). Unlike other givens he criticizes, Allport does not subject to scrutiny the classical liberal perspective that contraposes individuality and collectivity, assuming the latter primarily as a source of threats to negative freedom and the former as the provider of powers for self-realization or positive freedom. 
A consequence of this individualistic bias is that, despite socialization being important, Allport does not embark on an inquiry into the kinds of social organizations that enable or promote human becoming. He assumes it is characteristically and universally human (and widely distributed). Concrete human becoming, however, demands a wider perspective. In fact, other narratives on becoming are as strongly compelling without sharing the positive outlook on the powers of individual choice, motivation, and striving. Simone de Beauvoir famously remarked in The Second Sex (1953, p. 273) that "one is not born, but rather becomes, a woman" (for existentialists one is never born anything). For many women in Western societies, becoming woman is still characterized by a socialization into narrowly defined gender roles and expectations, forming a labyrinth of often contradictory constraints on aspirations in the form of injunctions, shaming, exclusions, condescension, and restricting narratives that steer and homogenize patterns of becoming instead of setting them free. These constraints go to the core of bodily powers and sensitivities and take root in lived experience (e.g., Young 2005). Becoming a woman today cannot be said to be driven in the main by a series of freely chosen goals. Similar counter-narratives describing systematic foreclosures to self-development can be raised from the viewpoints of race (e.g., du Bois 1903; Fanon 1952), coloniality (e.g., Césaire 1955; Fanon 1963), class (e.g., Charlesworth 2000), other forms of oppression, and their union/intersections (e.g., Lugones 2003).

In this less optimistic sense, the very nature of human plasticity makes experiences, events, short term choices, and social encounters have cumulative effects on individual development, sometimes locking personal becoming into particular paths, closing some options, imposing others, all with little or no reflective awareness. There is no clean distinction here between "tribal" and "individual" becoming. Social habitus (Bourdieu 1990) administers individual becoming by reproducing patterns of experience and behavior that reaffirm a given social order by regimenting attitudes, languages, and worldviews as well as by maintaining configurations of social capital and power (Charlesworth 2000).

Allport's self-driven becoming demands unusual opportunity and critical powers that create awareness of patterns that hijack human plasticity. Critical awareness can only be systematically developed as a social project. This leads us to consider Paulo Freire's influential work in critical pedagogy, which he developed from his own experiences in running popular literacy campaigns in Brazil and Chile (Freire 1974, 1996). Critical pedagogy is itself an example of its own message, viz., that consciousness demands a synthesis of transformative action and reflection in concrete situations - praxis. Critical education is a mutual transformation of teachers and students via concrete problem solving, the breaking down and re-constitution of given wholes, and sustained dialogues that create the conditions to change concrete realities and open new possibilities for action in our own personal and community processes of becoming.

Freire is inspired by the Marxist conception of human freedom. In the Grundrisse Karl Marx rejects the idea of freedom as being rid of the need to labor to deal with needs and obstacles; a sort of ultimate tranquility. Rather, "the overcoming of obstacles is in itself a liberating activity ... the external aims become stripped of the semblance of merely external natural urgencies, and become posited as aims which the individual himself posits - hence as self-realization, objectification of the subject, hence real freedom, whose action is, precisely, labour" (Marx 1973, p. 611). Through praxis, not only are aims realized in the overcoming of obstacles, but the aims themselves become 
posited as genuinely novel possibilities. For Marx concrete freedom through transformative activity is at the core of human becoming and is not possible for it to be fully realized by isolated individuals. It develops historically with different modes of social organization, until at some point a social mode of existence will produce "the absolute working-out of [human] creative potentialities, ... i.e. the development of all human powers as [an] end in itself, not as measured on a predetermined yardstick ... where [one] strives not to remain something [one] has become, but is in the absolute movement of becoming" (p. 488).

On a quick read, we see similarities between these passages and human becoming as conceived by Pico and Allport. A key difference lies in the the concept of praxis. Pico suggests it is up to us to choose our becoming, belying the fact that this statement does not apply to all human beings in his time or ours. Allport, like Marx, describes the way becoming depends on the unifying character-giving powers of longer term goals, bringing action, decisions, and striving into the picture. Yet he stays shy of examining the role played by sociomaterial factors in becoming. Overcoming obstacles is a liberating activity, in the same sense of freedom described by Marx. But even for those individuals favored by circumstances, there is still in Allport's account a disconnect between action and intention in that the latter freely plans a path like a general overlooking a map from the safety of headquarters, and the former attempts to follow that path confronting the actual terrain. In contrast, for Freire, action, consciousness, and world are dialectically related. Concrete human becoming, therefore, must be a striving in the form of praxis, i.e., intentions and actions that become increasingly integrated when confronted with concrete, often challenging realities. Crucially, it is up to communities to systematically change the barriers to the possibilities of freedom in attendance to people's vulnerabilities as much as potentialities. Praxis - participatory thought-in-action, critical embodied consciousness - has a footing in the world, so it stands a chance of transforming communities and world both.

Because thought-in-action demands awareness of concrete circumstances and awareness of our own powers and vulnerabilities, it is guided by reflection, which is itself socially constituted consciousness, its more concrete form being transformative dialogues. Thus, human becoming cannot but be a social process, an achievement of communities, not of individuals, who nevertheless can incarnate these social powers and put them into practice. As Elena Cuffari (2011, p. 548) says: "Education and training in practices of growth and transformation are required to live consciously and gracefully, and we need to be supported when we undertake practices whose selftransformative ends are unforeseen. We cannot control flexible habit formation on our own."

Freire is concerned with the sociomaterial conditions for transformative freedom. ${ }^{4}$ The possibility of free becoming originates in the combined fact that both human beings and the rest of nature are unfinished and that we are aware of this condition. "Problem-posing education affirms men and women as beings in the process of becoming - as unfinished, uncompleted beings in and with a likewise unfinished reality. Indeed, in contrast to other animals who are unfinished, but not historical, people know themselves to be unfinished; they are aware of their incompletion. In this

\footnotetext{
${ }^{4}$ Apart from Freire's own case studies (e.g., Freire 1974), there is a wealth of applications of critical pedagogy with students of all backgrounds and ages, (e.g., Au 2018, hooks 1994; Ledwith 2016).
} 
incompletion and this awareness lie the very roots of education as an exclusively human manifestation." (Freire 1996, p. 84). Education, whether formal and systematic or through growth into a social habitus, apprenticeships, learning a language, etc. is a constituent of human consciousness and a way the powers and vulnerabilities of becoming are managed within a community.

Freire predicates about societies what Pico predicated about individuals. The potentialities and vulnerabilities are there for communities that make concrete becoming a reality for all and not a privileged few. But societies may or may not go this way. Critical pedagogy is therefore a project aimed at driving a sort of hyper-becoming, the historical becoming of societies and their environments ${ }^{5}$ capable of enabling the free becoming of individuals. Marx's and Freire's ideal society would be one that makes Pico's and Allport's views a material reality for each and every one of its members according to their given and chosen differences. In sum,

Human becoming: constitutively social; unfinishedness of humans and world; potentialities not always available to individual effort and choice; a historical possibility that may be socially enhanced or limited (hyper-becoming); requires educating critical powers for reflection, praxis, and social action.

These increasingly specific indications of human becoming help us come back to the question of how we should think about human bodies. It is clear that we must distinguish, but not fully dissociate, different dimensions of embodiment with different senses of becoming. Being alive, being a sensorimotor creature, being a potential incarnation of powers and sensitivities that have been historically developed in human communities, and being a participant in the historical transformation of the world. Taking all of these entangled dimensions into account is part of the desiderata of any truly embodied approach to human minds.

\section{The neotenization of individuation in Simondon}

Moving from an existential to an ontological register, we briefly explore Gilbert Simondon's philosophy of individuation with the aim of finding parallels to the structures of human becoming indicated in the previous section and shaping a framework that can guide the theoretical articulations of the next one.

Simondon's philosophy is a radically nondualistic ontology of becoming or, to be more precise, a study of ontogenesis. ${ }^{6}$ Behind every thing that exists in time there are past and present processes that produce it. Nothing is immutable and self-standing or magically appearing unconditioned or unproduced. For Simondon, a philosophy that

\footnotetext{
${ }^{5}$ We do not develop the question here, but entering into braided and co-evolving relations with non-human individuals (other species, the land, the planet) is an implicit requirement for such a project to succeed (see e.g., Kimmerer 2013).

${ }^{6}$ See (Simondon 2009); this is a densely packed introductory essay in his main work on individuation (Simondon 2005) and one of the few sections of this book currently available in English translation (a full translation is forthcoming in 2020).
} 
starts from the properties of individuals in their finished form and not from the principles of individuation arrives too late at the scene.

We can only summarize Simondon's philosophy of individuation very briefly here. Our goal is not to present a critical analysis of his work. For our purposes, it will suffice to place human becoming within a larger set of Simondonian categories of individuation and realize that it expresses a tendency in how these categories relate to one another (through the idea of neotenization).

Simondon developed his main work during the 1950 s and 1960 s. $^{7}$ He combined a deep engagement with the history of ideas, science, and technology with a practical, hands-on interest in machines and technical knowledge, placing him in the company of the pre-Socratic philosophers he much admired. One of his critical targets was hylomorphism, the Aristotelian doctrine that individuals come to exist as a combination of matter and form, typically meaning the active effect of form on inert matter. This abstraction hides the fact that in every process of individuation something else is going on, an encounter between large and small scales, between different temporalities, a transaction between flows of active, organized, and organizing matter. Simondon suggests hylomorphism is the result of a particular social organization that separates those who work in technical production from those who own and direct it. The concreteness of technical individuation can only be missed from the detached perspective of someone who is only interested in the abstract properties of inflows and end products and who is not required to prepare matter into homogeneous and formative phases, and into active and passive roles (Simondon 2005, p. 57-60). This abstract mode of thought, it can be argued, is at the root of all of the dualisms that populate the history of Western philosophy.

Technical production, widely understood, consists in directing and setting in motion modes of physical, organic, psychic, and collective individuation. Such processes, of course, also take place on their own. For Simondon all of these forms of individuation originate in material operations that mark a passage from what he calls the preindividual to the co-emergence of an individual and its associated milieu.

The preindividual is the undifferentiated condition of nature in the absence of distinct phases, before undergoing determinations. It can take the form of metastable, far from equilibrium, or critical dynamical states before an event triggers a process of individuation and some possibilities become determined and phases actualized. The preindividual recalls Anaximander's ő $\pi \varepsilon\llcorner\rho o v$ (apeiron), the boundless, infinite, active

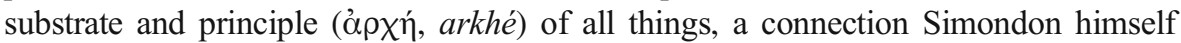
makes (Simondon 2005, p. 297; Duhem 2012).

Physical individuation happens in processes such as phase changes in condensed matter. Simondon's running example is crystallization. A supersaturated liquid solution in a metastable state (containing potential energy but not enough of it for the spontaneous nucleation of crystals) provides preindividual potentialities, some of which become realized as soon as a chemically compatible seed is introduced in the system. The system de-phases itself: the process of crystallization propagates forming an individual crystal, with properties that depend on the general conditions of potential energy in the

\footnotetext{
${ }^{7}$ Apart from his ontology of individuation, Simondon developed several epistemological implications of his philosophy dealing with problems of perception, affect, creativity, imagination, and ethics. His other major and related line of work concerns the philosophy of technology (Simondon 1958).
} 
solution, the pattern, shape, orientation, etc. of the seed (some compounds can crystallize into different lattice formations), the boundary conditions, and on historical variations and contingencies in these factors. The resulting state is more stable and organized than the original one (intermediate states of organization/metastability are also possible as in the case of liquid crystals, gels, different lattices, etc.). Individuation is the outcome of a particular history of events, its conditions are conditions of actuality. It occurs through an operation of transduction, a propagation of structuring activity, at the active boundary between phases. Transduction amplifies the initial interaction between seed and medium and builds order at the interior of the crystal, coordinating structural and other physical properties across different orders of magnitude (the active process is microscopic, the results are macroscopic with measurable properties such as anisotropies in electromagnetic fields, regular recurrent shapes, planes of rupture, etc.). We may differentiate between the individuated phase (the organized lattice), the activity (crystallization at the boundary) of the individuation process, and their associated milieu (the liquid solution).

Crystallization serves as a model for other kinds of individuation. Organic individuation, the material constitution of living bodies, operates on the same basic principles: a passage from preindividual sources of metastability, potentiality, energy, and novelty towards a more stable, organized, and internally related individual that is at once intimately connected to and distinct from its associated milieu. The main difference, however, is that the passage towards states of lower potentiality is slowed down, deferred in time, by means of inducing or finding new sources of preindividuality before the process runs down. It is as if the advancing frontier of crystallization were turned on itself preventing the more organized phase from fully settling into a stable form from which no further individuation can occur. Organic individuation is therefore fundamentally an unfinished process. Living bodies must preserve and renew sources of preindividuality both in themselves and in the environment, so as to continue to individuate (the preindividual is not only present at the start of the organic process of individuation, but as long as it remains active). This can take many forms depending on the specific biochemistry, from transducing external nutrients into intracellular chemical currencies (e.g., ATP molecules), through processes of rest and tissue regeneration, to inducing waves of neuroplasticity when learning something radically new. Organisms live in the thick boundary of the process of individuation, at the meeting point of microscopic and macroscopic orders, at the ambiguous limit between potentiality and structure, incipient future and not-yet past.

This mode of existence distinguishes living bodies from machines.

"[T] he living cannot be reduced to an automaton that maintains a certain number of equilibriums ... [the living] is the result of an initial individuation and that amplifies this individuation - an activity not undertaken by the technical object ... There is, in the living, an individuation by the individual and not only a functioning that would be the result of an individuation completed once and for all, as if it had been manufactured; the living resolves problems, not only by adapting itself, that is to say by modifying its relation to the environment (which a machine can do), but by modifying itself, by inventing new internal structures 
and by completely introducing itself into the axiomatic of vital problems." (Simondon 2009, p. 7, original emphasis).

Moreover, also unlike machines, organic individuation engenders a veritable interiority.

In the physical domain, internal resonance characterizes the limit of the individual that is in the process of individuating itself; in the living domain, this resonance becomes the criterion for the individual in its entirety insofar as it is an individual; ... The internal structure of the organism is not only the result (as with a crystal) of the activity that occurs and of the modulation that occurs at the limit between the interiority domain and the exteriority domain. The physical individual, perpetually de-centered, perpetually peripheral to itself, active at the limit of its domain, does not have a veritable interiority; the living individual, on the contrary, does have a veritable interiority because individuation carries itself out within the individual; the interior is also constitutive in the living individual, whereas in the physical individual, only the limit is constitutive, and that which is topologically interior is genetically anterior. The living individual is contemporary to itself in all of its elements, which is not the case for the physical individual, which carries something of the past that is radically past, even when it is still growing. (ibid.)

The living organism regulates the relations between interior and exterior (sensations) and between individuated phases and preindividual potentialities (affects) to keep individuation viable. Simondon uses the term psychic individuation to describe the operations that are enabled by the participation of the organism in its environment and are aimed at the problem space posed by its regulatory demands. These are "problems" that emerge from organic individuation (finding appropriate environmental conditions, regulating exchanges across boundaries, protecting the interior domain, etc.). "The psychic is the continuation of the vital individuation in a being that, in order to resolve its own problematic, must itself intervene as an element of the problem by its action, as a subject." (ibid. p. 8, emphasis removed).

Psychic individuation occurs through engagements, coordinating sensations and affects into recognizable forms of action, perception, and emotion. Engagements always connect the interior and the exterior, the individuated and the preindividual, they do not belong purely within either of these domains.

But in establishing this regime by which psychic and somatic individuation mutually enable each other, new problems emerge. The unindividuated potentialities, the excesses and lacks of a psychic individual do not always meet the required conditions. This leads to states of frustration and anxiety. For Simondon, these problems can only find resolution in collective individuation. A subject (i.e., a living body that carries a charge of unindividuated potentiality) finds further individuation in the life of the group, "linked to the group by the preindividual reality that it carries inside itself and that, when united with the preindividual realities of other individuals, individuates itself into a collective unity" (Simondon 2009, p. 8). To this idea of collective individuation as intimately linked to the transformation of organic tensions into psychic ones (frustrations, threats, anxiety) corresponds the concept of transindividuality, the mutual 
determinations of inner preindividuality among subjects in a collective. Transindividual individuation is the "systematic unity of the interior (psychic) individuation and the exterior (collective) individuation" (ibid.). It is not a relation between given and finished individuals but an engagement involving interiorities and exteriorities in mutual determinations of unresolved preindividuality. It requires an opening up of the living interior to the participation of others.

Transindividuality is an idea with many ramifications, short-circuiting as it does various orders of reality: material, organic, psychic, political, historical (e.g., Balibar 2018; Combes 2013; Read 2015; Virno 2015). For our purposes, it suffices to note that human becomings of the kinds discussed in the previous section are made possible through transindividual individuation. Using the term "individualization", Simondon sees the origin of personality and styles in the transindividual.

Challenging the prejudice that makes us pitch individual singularity against the community-i.e., contra Allport's distinction between tribal and personal becoming and lending support to Freire's critical project - transindividuality is the condition of possibility of concrete human becoming. Simondon's ontology clarifies what others already knew well: "Man is a zoon politikon in the most literal sense: he is not only a social animal, but an animal that can be individualised only within society" (Marx 1970, p. 189, emphasis added). Paolo Virno (2015) similarly notes that participation in a community is an affirmation of individuality, not a loss of it.

While the passage from physical individuation to organic, psychic, and collective individuation at times resembles a "chain of being" narrative that moves from the relatively simple to the complex, from self-assembling matter to human societies, a closer look tells a different story. Like with the case of individual singularity enabled by collectivity, the relation between the different categories of individuation literally inverts the main elements in most narratives of progression. Yes, more complex forms of individuation have appeared through history and yes, they can often be understood at least partially in terms of simpler antecedent evolutionary or historical conditions. But the principles of individuation reveal that, ontologically, the complex is not built upon the simple; it results instead from avoiding becoming simple.

The pattern is clear in the difference between physical and organic individuation, and is repeated with each new category of individuation. Unlike physical individuals that eventually exhaust their sources of potentiality, organic individuation does not fully use its sources without first renewing them (for as long as the organism lives). Simondon describes this as a neotenization of physical individuation:

"It is customary to see in vital processes a larger complexity than in non-vital, physicochemical processes. However, ... we would suppose that vital individuation does not come after physicochemical individuation but during this individuation, before it is finished, suspending it at the moment when it has not yet reached its stable equilibrium, and rendering it capable of extending and propagating itself before the iteration of the perfect structure capable only of repeating itself, and this would conserve in the living individual something of the preindividual tension ... under the form of an internal resonance between extreme orders of magnitude" (Simondon 2005, p. 152). 
In evolutionary biology and physical anthropology, neoteny refers to a comparative slowing down of rates of growth, the retention of juvenile features, and the prolongation of developmental periods prior to maturity (e.g., Montagu 1989). Much has been made about neoteny in the genus Homo compared to other primates and the relevance of prolonged periods of learning and socialization that are universally found in human cultures. These are interesting ideas and they relate to Simondon's interpretation scheme in terms of neotenization, but the implications of the latter are more profound.

Each more sophisticated mode of individuation consists in finding ways to avoid the more determined stages of more basic individuation processes, by entering into determinations that postpone other determinations, keeping potential options open for longer periods and creating new possibilities. ${ }^{8}$ In psychic individuation some of the determinations of organic life are modulated by the contextual situation by turning them into new actions, selection of possibilities, sensitivities to upcoming events, etc. For example, learning to walk using a cane and becoming more sensitive to sounds bouncing off the walls is a psychic determination that defers in time, potentially indefinitely, the reduction in navigation skills due to loss of vision in a blind person. Transindividuality also has the effect of sustaining potentials that would otherwise get lost in order to introduce new elements of choice at the community level (through technological mediation, medical practices, co-operative organizations, etc.).

Problems that are resolved by a reflex circuit in some forms of life, remain open to developmental adjustment according to environmental variation in others. In some species these problems are open to lifetime learning, in others to social norms, to reflective and critical consciousness, and so on. Human becoming is possible because through historically changing patterns of transindividuation we have found the means of retaining as open options decisions other animals cannot entertain. In this way, the neotenization interpretation closely interlocks with the conscious unfinishedness that motivates Freire's critical pedagogy (and validates its target of changing societal relations in order to change human becoming). It is sufficient to think of how social organization, widely construed technologies, reflective knowledge, and (a degree of) self-empowerment can in some cases allow groups of individuals in contemporary societies to challenge the paths of determination that would have severely restricted their powers of individuation (at all levels), for instance in the case of illness, injury, etc., not to mention the possibilities that are opened to meet new needs in ways that were out of reach in the past, a striking case being the access to hormone suppression and replacement treatment and surgery for transgender people. ${ }^{9}$

\footnotetext{
${ }^{8}$ The ontological novelty introduced by the preindividual and a proper attention to the temporal character of individuation clarify the sense in which possibilities and potentialities can be created precisely through actual determinations, thus altering the traditional conceptual relation between the possible and the actual. Here Simondon's ontology may fruitfully be compared with Merleau-Ponty's theory of expression (e.g., Landes 2017) for whom an act of expression does not follow a determinate intention but is itself constitutive in determining it. This backward influence is not merely epistemic, see e.g., Di Paolo (2015) and Maclaren (2017) (who nevertheless prefers the more epistemic term "retrospective" to "retroactive").

${ }^{9}$ In this condensed account I am not touching on entanglements between different forms of individuation, from holobionts to ecosystems to technoscientific societies. Suffice it to mention that, since the onset of agriculture, there are few processes of physical and organic individuation on Earth that have remained unaffected by human transindividuality.
} 
The history of individuation extends the reach of organizing matter further back into the ö $\pi \varepsilon\llcorner\rho \circ v$, into the preindividual. The naturalistic fallacy does not consist therefore in wrongly deriving moral guidelines for human becoming from other forms of life simply because humans have somehow transcended such forms. It consists in wrongly placing human becoming as ontologically posterior to animal becoming when in fact it consists mainly in avoiding becoming animal. We may not succeed in this and, like Pico said, go the way of the beasts. Animals have no other option. What they do, therefore, cannot have a principled direct ethical hold on what we do. Even if we find good examples in the rest of nature for our dilemmas, it is still up to us to choose to adopt them as moral guidance.

\section{Modes of becoming in the enactive approach}

There are several convergences and complementarities between the enactive approach and Simondon's philosophy of individuation, which, to an extent, facilitate the passage from ontology to a theory of human bodies as concrete becomings. A full discussion of these links is beyond the scope of this article, but a few points may be mentioned.

Simondon's ontology seeks to unify different spheres under an assumption of continuity. What enactivists describe as the continuity between life and mind using the idea of autonomy (Varela 1997; Di Paolo and Thompson 2014), takes on in Simondon the shape of the principle of individuation (explicitly extending the reach of continuity to the physical domain). Although both approaches are nondualistic and reject the idea of the machine as a model of organic and psychic individuation, there are several important aspects of Simondon's work that are currently missing in enaction. We could mention the insistence on individuation of all kinds entailing the meeting between different orders of magnitude, the energetic conditions that make individuation possible, the events and conditions that actualize it, the thematizing of preindividuality, and a more explicit account of how domains of interiority and temporality emerge in organic individuation.

An apparently significant difference that I see as not difficult to reconcile is that the enactive conception of life and mind makes reference to negative aspects of materiality (notably the concept of precariousness) and Simondon often avoids speaking of lacks or privations, possibly as a result of his distancing from Aristotelian and Hegelian traditions. Instead, the world is a source of "positivity" in that from the preindividual new possibilities are constantly set in motion. Simondon does not spend too much time discussing negativity (there are some passages on the corrosion of crystals and the anxiety of unresolvable tensions). This difference could be interpreted as a significant metaphysical break but I see no contradiction in speaking of the positivity of active matter and acknowledging that an "excess" of unexpected change can induce the destabilization of processes that an organism must rely on to survive, making these processes effectively precarious from the organism's perspective and in need of ongoing regulation and regeneration. Precariousness entails that the conditions for a living body to operate are unwarranted and must be constantly produced and regulated. This is another way of saying we should expect things to be subject to change; whether positive or negative can only make sense according to vital norms (Merleau-Ponty 1942; Thompson 2007). In other words, the negativity of precariousness in organic 
processes and the positivity of the preindividual cannot be directly contrasted; they are in fact compatible ideas. ${ }^{10}$

What is also novel for the enactive approach is Simondon's scheme of interpretation linking progressively complex forms of individuation with the idea of neotenization. This scheme can be useful in interpreting the dimensions of embodiment in terms of increasingly open modes of becoming. With this we can give a more explicit shape to the enactive answer to our initial question about what counts as a body while keeping the constraints we have set ourselves in sight: a naturalistic life-mind continuity perspective, on the one hand, and the possibility of accounting for concrete human becoming, on the other.

Three dimensions of embodiment have been the focus of work in the enactive approach: organic, sensorimotor, intersubjective (Thompson and Varela 2001). The overlap with Simondon's organic, psychic, and collective forms of individuation is not exact, but the ideas are compatible.

Organic individuation occurs in autopoietic systems, which require the joint conditions of self-production and self-distinction (Maturana and Varela 1980, 79). A network of physicochemical processes is self-producing if, through their operation, these processes regenerate the same network of enabling relations. It is self-distinguishing if it actively sustains a topological arrangement that keeps the network distinct from its environment. In the classical theory of autopoiesis not much is said about the relation of these two conditions. As a consequence, processes and events that occur at the level of the organism-environment relation (self-distinction) have been rendered conceptually distinct from processes of metabolic constitution (self-production). Such a situation has kept life processes and cognitive/affective phenomena forever separate. Starting with the late work of Varela (1997; Weber and Varela 2002), enactivists have questioned this separation postulating that there is an internal relation between autopoiesis and sensemaking, that is, the way a whole organism engages the environment in terms of norms, valences, and meaning. It is precisely because of the conditions of autopoiesis that an encounter with the environment acquires a positive or negative valence, insofar as it contributes or not to self-individuation. This is more firmly established by demonstrating that autopoietic systems can also show adaptivity, an operational property that allows an organism to regulate its coupling with the environment according to its own conditions of viability (Di Paolo 2005).

We note that to ask of a concrete material system that it be simultaneously selfproducing and self-distinguishing induces a dialectical situation (Di Paolo 2018). A tendency towards improving the conditions for self-production is also a tendency towards opening the system up to a wider set of environmental flows to take advantage of so as to continue to self-produce in as many environmental conditions as possible

\footnotetext{
10 This difference is manifested in Simondon's criticism of Hegelian-style dialectics. He questions whether a synthesis between concrete tensions is ever a real overcoming or just a transformation (Simondon 2005 p. 111). Some interpreters make much of this distancing from dialectics. However, it is abundantly clear that Simondon constantly makes use of the motif that tensions necessitate innovative forms of individuation to be transformed into a novel set of problems. For some, this is textbook materialist dialectics, if we understand the method non-dogmatically. In a short essay, Simondon (2016) discusses the notion of a dialectical situation in terms of potentialities for change and barriers to change leading to antagonisms. The emphasis is on the concreteness of the situation rather than on the mental operation of seeking inner contradictions in the formulation of an idea. This is very much in resonance with how enactivists use dialectics (see discussion in Di Paolo et al. 2018).
} 
("everything is food"). A tendency towards improving self-distinction moves in the opposite direction, reducing the chance that environmental flows will threaten the individuality of the organic system, which ideally ends in isolating the system entirely ("everything is a threat"). In neither case, maximal self-production or maximal selfdistinction, do we have a living system. The dialectical resolution of this tension is the regulated deferral of openings and closings to environmental influences that keep the system viable. Such regulation with respect to viability conditions is what we have called sense-making. Unlike classical autopoiesis, which remains hylomorphic, (DiFrisco 2014), in the enactive conception to be a concrete material living body is to be a sense-maker or an agent.

There is a parallel between Simondon's organic and psychic individuation and this enactive conception of life, in that organic individuation creates a space of problems that psychic individuation deals with. Concrete autopoiesis in materially and thermodynamically realistic conditions, likewise, entails adaptivity and sense-making due to the inherent tension the living condition creates. Moreover, an explicit temporality (absent in classical autopoiesis) is implied in that sense-making, like organic individuation in Simondon, operates at the thick limit between incipient future and not-yet past (Di Paolo 2005). The enactive conception of life is an organic mode of becoming because it operates via unceasing adaptive regulations of the organic body in the face of external uncertainty and as a result of its own primordial tension.

Psychic individuation also covers the sensorimotor dimension of embodiment, the cycles of regulation of action/perception/emotion in loops of sensorimotor and neurohormonal-musculoskeletal activity. Autonomy, sense-making, and agency help us make sense of the sensorimotor dimension. In turn, these ideas are transformed by the set of problems we must face there, problems about the roles of brain, body, and world in how perceptual experience is constituted, how action and perceptual skills are mastered, and so on. Di Paolo et al. (2017) address some of these questions in terms of sensorimotor mastery (via an operationalization of Piaget's theory of equilibration). In a nutshell, repertoires of sensorimotor schemes (normatively organized patterns of coordinated body-world couplings) undergoing processes of plastic equilibration assemble themselves during development into networks that link schemes functionally and structurally to each other. These networks form clusters, some of which are selfsustaining: habits. Habits both predispose and demand repeated enactments according to their own norms (which can be in tension with the norms of organic selfindividuation; as anyone who tried to overcome an addiction knows). If and when the organization of the whole repertoire becomes itself autonomous (i.e., integrated parts of the whole repertoire become self-sustaining), then a new form of agency, a sensorimotor mode of becoming or sensorimotor body, emerges.

The enactment of a sensorimotor scheme, in these conditions, is a reaffirmation or a challenge to a self-sustaining set of relations in the whole repertoire. In addition to any biological relevance, the sensorimotor organization is reasserted by every successful act and challenged by breakdowns, through spreading processes of mutual equilibration between schemes. In this way, particular sensorimotor styles reflect a history of engagements with the world, but at the same time constitute the motives, dispositions, and skills that mobilize a sensorimotor body.

Notice how the idea of sensorimotor becoming changes our conception of bodies. We are not only speaking here of organic bodies, but also about their relational and self- 
individuating modes of operation in the world. Sensorimotor bodies are assembled by processes of networked relations between precariously equilibrated sensorimotor schemes, they are literally made by organized potential and actual enactments. ${ }^{11}$

In a precise sense (operational closure of relations between schemes in a repertoire), sensorimotor bodies are enacted into existence. They bring forth a world of significance by acts that simultaneously change bodies and environment. This mode of becoming is a sensorimotor unfinishedness, not merely an opening to changing demands and circumstances but a constructive activity by which sensorimotor bodies and their codefined environments change historically at behavioral, developmental, and evolutionary scales. In the human case, developing sensorimotor bodies are open-ended and path-dependent or non-ergodic (Di Paolo et al. 2017, pp. 101-106).

Sensorimotor bodies, moreover, are enacted together. While the kind of phenomena that occur during collective individuation in Simondon's account remain relatively general, enactivists have proposed to apply the idea of autonomy to the dynamic patterns of social encounters, introducing the concept of participatory sense-making (De Jaegher and Di Paolo 2007) to describe the general condition of mutual affectivity between bodies in interaction. There are in social encounters situations where the sensemaking of a participant is literally modulated or enabled by the activity of others, and in some cases, sense-making is constituted jointly in co-authored social acts (De Jaegher et al. 2010). Insofar as this can only happen while individuals do not fully lose their condition as autonomous agents, social participation requires a regulated openness towards the influence of others, and acceptance (that I can still withdraw) for others to intervene in my own acts, perceptions, and emotions, changing them, finding new meanings in them, making them part of a flow that I do not fully control in ways I have not initially intended. In the sense that I am not the sole determinant of sensemaking during social interactions that bring into contact different orders of magnitude, from the biochemical to the societal, participatory sense-making is the enactive correlate of transindividuality.

The effects of participatory sense-making on sensorimotor bodies is even manifested in non-interactive conditions (Di Paolo and De Jaegher 2012). Fuchs and De Jaegher (2009) interpret Merleau-Ponty's (1945/2012) conception of prereflective intercorporeality as mutual incorporation, the phenomenological counterpart of a readiness to interact which develops through social micro-practices. This radically

\footnotetext{
$\overline{11}$ Two common prejudices must be abandoned to make proper sense of this idea. The first prejudice is to see bodies only in terms of anatomy and physiology. Our bodies are indeed organic, but we also have daily and phenomenologically informed reasons to conceive of them as bundles of activity, or as William James put it "bundles of habits": what they do, what they express, what they care about, their powers and sensitivities. In a nondualistic perspective these active, minded aspects are not separate from the constitutive conditions that make a body the body it is (provided we can indeed prove that these conditions are met in sensorimotor bodies, as shown in Di Paolo et al. 2017). The other prejudice is a narrow conception of action, one that reduces an act to an overt event and does not see it rooted in a set of relations to other acts (enabling, priming, inhibiting, alternatives, etc.) and other body and environmental processes. The overt phase of act the tip of the iceberg, as the pragmatists have argued. For George H. Mead every single action organizes into immediate alternative possibilities, necessary exclusions, and other relations (e.g., Mead 1932, pp. 127-128). John Dewey insisted that each habit has an underground existence, operating "all the time during waking life; though like a member of a crew taking his turn at the wheel its operation becomes the dominant characteristic trait of an act only occasionally or rarely" (Dewey 1922, p. 29). See also (Sullivan 2001) on conceiving bodies as transactional activities from a pragmatist-feminist standpoint, (Korsgaard 2009) on agency as constituted by acts, and (Mol and Law 2004) on the daily practices of doing bodies.
} 
changes sensorimotor becoming: powers and sensitivities develop in interaction with the powers and sensitivities of others within concrete sociomaterial situations. This is obviously the case in early human development where caregiver-infant interactions can guide sensorimotor development by inducing disequilibrium in the infant so as to prompt her at different stages either to diversify or consolidate her sensorimotor powers and sensitivities (Di Paolo et al. 2017, pp. 239-246). But it remains the case throughout the whole lifetime. Participatory or intersubjective becoming is again different from sensorimotor becoming in that developing sensorimotor bodies must retain (or regain) enough preindividual potentiality in order to engage, through socially induced individuations, with the norms, customs, and history of a community. Organic and sensorimotor norms are put in contact with sociomaterial patterns, powers, and constraints. Socially developing bodies must navigate the uncertain terrain of making sense of these different normative orders.

All of the foregoing applies to human becoming, but much of it applies to other forms of life too. Specifically human patterns of becoming have been explored in the enactive approach in broad terms that consider the cultural embeddedness of human bodies (e.g., Thompson 2007). But there is a gap between the concepts of sensorimotor schemes, repertoires, powers, etc., and the vocabularies used to describe human sociality and language making the connection of these two areas of embodied cognition research not impossible, as work in cognitive linguistic has shown, but still open to skepticism.

Recent work proposes new categories for social agency to bridge the conceptual gap between sensorimotor agency and language. I can only give here a brusque summary of the model of embodied linguistic agency proposed in (Di Paolo et al. 2018), which in essence follows the dialectical model presented by Cuffari et al. (2015). Situations of participatory sense-making engender a basic tension, an ever-present risk of disharmony between the individual participants and the dynamics of the social situation. The management of this tension with increasingly complex forms of social agency is the thread that guides the engendering of novel categories moving from sensorimotor to linguistic bodies.

A first way of coping with disharmonies between interactive and sensorimotor norms is by co-regulated social acts, that is, acts that can only be enacted together, such as shaking hands, or giving/receiving an object. These acts sediment in the repertoires of frequently interacting bodies in the form of partial schemes (givingreceiving) and so in a group of frequent interactors sensorimotor bodies become, to an extent, co-defined with other bodies. Partial acts can also be used recursively to help participants resolve the problem of coordinating schemes with each other (think of an offering gesture accompanied by a nod to encourage a hesitant receiving gesture in another person). These regulatory partial acts introduce potential asymmetries in the interaction, which require some kind of time-management in order for the interaction not fall under the orchestration of a single agent (a condition that would break interactive autonomy). Eventually the use of strongly normative or regulatory partial moves in the interaction is acceptable by other participants if in principle all participants can at some point occupy this role. Interactions of this kind again demand an opening to others, a form of letting be (see De Jaegher 2019). There is a deferral in time that organizes interactions into turns of regulatory interventions on the part of one participant, and acceptance on the part of the others, provided roles switch at some point. This is the beginning of a dialogical organization. 
What is interesting about dialogues is that interventions in them (we can call them utterances, but they include all kinds of gestures, demonstrations, etc., used in a particular way, and not only spoken or signed acts) have properties beyond the pragmatic force of sensorimotor schemes. They are also interventions that 1) are sustained and enabled in part by an audience, 2) demarcate certain interpersonal relations (e.g., speaker/audience), 3) serve to identify the producer as a person (e.g., through addressivity), and 4) for this last reason, their expressive aspects become expressions of the body that produces it. Utterances, thus, have person-constituting powers and dialogues permit the possibility of mutual interpersonal recognition.

Utterances, like other partial acts, can also be recurrent and resolve particular tensions that emerge in dialogues (such as when participation genres are ambiguous, e.g., is it a friendly conversation between boss and employee, a request, or an order?). They do so by the power of reporting or reflecting other utterances, and in general resonating with some of their properties. Most live conversations are constructed together by resonances, repetitions, transpositions, etc. of previous utterances (Du Bois 2014; Goodwin 2018). This make utterances have the property of braiding together, ultimately linking to absent voices, texts, jokes, songs, etc.; in other words, interweaving with language as a living historical stream.

Dialogical agency is not simply a new skill added on top of others, but a wholly transformative development of participatory becoming, a way human history takes root in human bodies.

"The single adequate form for verbally expressing authentic human life is the open-ended dialogue. Life by its very nature is dialogic. To live means to participate in dialogue: to ask questions, to heed, to respond, to agree, and so forth. In this dialogue a person participates wholly and throughout his whole life: with his eyes, lips, hands, soul, spirit, with his whole body and deeds" (Bakhtin 1984, p. 293).

We cannot conceive of language as a reified abstract system in this view, something wholly external to our bodies. Language is not separate from the stream of concrete language use; it is that stream. It is not tossed like a ball from generation to generation. "Language cannot properly be said to be handed down - it endures, but it endures as a continuous process of becoming. Individuals do not receive a ready-made language at all, rather, they enter upon the stream of verbal communication; indeed, only in this stream does their consciousness first begin to operate" (Voloshinov 1929, p. 81, emphasis added).

But this is a point where a tension without a resolution is reached. This is a tension that defines linguistic agency and makes human becoming a perpetual task. It consists in the fact that by incorporating the skills for participating in linguistic communities a body must make existing patterns of gesturing and speech her own. There is an incorporation of the powers given by the use of utterances, by accents, vocabularies, idioms, expressive styles, etc. which makes use of and partially transforms linguistic materials that exist in the stream of language. This is the way a linguistic body is constituted, in analogous manner as a sensorimotor body is constituted by acts. But utterances are no ordinary acts, they are person-constituting and therefore they carry the 
traces of other agencies, the self-distinctions of voices of those who uttered them before, a family member, a friend, a character in a novel, a popular song, a slogan, a cliché, etc. Each act that reaffirms our linguistic agency is an act that summons other linguistic agencies, an act of incarnation. This is why language is so effective for selfcontrol. We can treat ourselves as an other, displacing our center, because we incarnate voices of authority, appeals to calm in the face of turmoil, or calls to action to mobilize ourselves.

This is the paradox of linguistic becoming, which because of the constitutive powers of language, is also the paradox of human becoming: to always navigate the uncertain waters between incorporation and incarnation of linguistic acts. In resonance with Freire, the becoming or unfinishedness of linguistic bodies is what permits human becoming to be dominated by powers that constrain free development and it is at the same time the condition of possibility of rebellion and struggle for new meanings.

A linguistic body continuously assembles herself using the acts of other linguistic bodies (including, of course, her own). For this reason, she learns to see herself as some body through the language of concrete or abstract others. This creates the possibility of oppression through the incarnation of agencies and the incorporation of discourses that manipulate a linguist body's common sense, alienate her powers and sensitivities, deskill them, and suppress spontaneity. But it simultaneously creates the possibility of emancipatory struggle through reflectively aware action by incarnating accents of liberation that transduce ideas, affects, motivations, and skills to from one body to another, and by incorporating critical discourses that foster the building of communities of care, powers, and vulnerabilities. ${ }^{12}$ Freire's critical pedagogy can be interpreted as the project of raising awareness about these constraints and these possibilities. We can submit to obstacles by reifying them as unavoidable parts of the natural order, or plot paths for change in ourselves, the world, and others in trying to overcome them in praxis (regardless of whether we succeed or not). This is at the root of self-driven human becoming of the style Pico and Allport celebrate. But it is a fundamentally social power, even when a single person wields it. In fact, it is a power most often enacted by groups of people. The self-reflectively aware unfinishedness that Freire sees in the human condition is rooted in the inherent tension in the condition of being linguistic bodies.

The enactive approach offers conceptions of bodily becoming in resonance with Simondon's ontology and fitting the existential structures indicated earlier. From an enactive perspective, to be a body is to be an entanglement of different modes of

\footnotetext{
12 This tension is everywhere language takes its hold, but its paradoxes are more noticeable in situations of oppression. Fanon (1952) dedicates the first chapter of Black Skin, White Masks to this ambivalence. "The Negro of the Antilles will be proportionately whiter-that is, he will come closer to being a real human being - in direct ratio to his mastery of the French language. I am not unaware that this is one of man's attitudes face to face with Being. A man who has a language consequently possesses the world expressed and implied by that language. What we are getting at becomes plain: Mastery of language affords remarkable power". But, at the same time that the language of the oppressor is incorporated, one installs racialized meanings and devalues other cultural forms, consequently curtailing the original subjectivizing powers of the language of the oppressed. The same paradoxes are explored by bell hooks in an essay on language in (hooks 1994) concerning the exclusion of black vernacular in higher education settings in the US. The tension can be read with a hopeful tone in that, as hooks argues, black vernacular has a power to intervene at the boundaries of standard English as a locus of resistance but also of counter-hegemonic creativity.
} 
becoming (organic, sensorimotor, participatory, linguistic), i.e., a stream of processes of navigation of the changing relations between body and non-body. These modes of becoming can be described operationally, making this approach one that not only acknowledges the crucial role of bodies, but also articulates the concept of bodies itself, thus positively addressing the opening question of this article.

\section{Replicant becoming}

From this point we could move in several directions touching on urgent questions that concern identity, community, individual and collective powers and vulnerabilities. But in an attempt to pin down the entangled complexities of the becoming of human bodies it may be informative to explore the question of what other beings might achieve similar combinations of historical rootedness and unfinishedness. We could explore companion species, enculturated animals, from the perspective of what factors may help produce the necessary developmental slowing down and transindividuality described by Simondon. ${ }^{13}$ Or we may speculate about alien paths to personhood, knowing at least some of the stages and categories at which divergences with the human case might occur (speculative fiction is a rich source for exploring such questions, e.g., Shaviro 2015). Instead, I will briefly examine the issue of artificial bodies. If the foregoing is on track, it should help us shed light on the plausibility of creating bodies like our own, understood in the enactive sense. ${ }^{14}$ As I will suggest, this cannot be realistically done unless the process of artificial creation also sets in motion a process of real personal becoming.

In Ridley Scott's 1982 film Blade Runner, Rick Deckard-voicing the dualism that made his homophone French philosopher famous - spells out a philosophy predicated on the separation between knowledge and value, begging the question of the mechanical nature of bodies. "Replicants are like any other machine. They're either a benefit or a hazard. If they're a benefit, they're not my problem". To which Rachel, herself a replicant unaware of her condition, responds with a question that, were it not interrupted by Tyrrell's entrance, would inevitably lead Deckard right into the contradictory heart of his dualism: "Have you ever retired a human by mistake?"

The risk of such an eventuality is what introduces the viewer to the epistemic conundrum of the film. Replicants appear human. So much so that the material evidence that they are not, that they are manufactured, such as serial numbers microscopically engraved on skin or bones, remains unconvincing after witnessing their behavior, their motivations, their emotion. We must be die-hard Cartesians to discard the experience of observing or interacting with replicants, to think they are mere machines. Contra Simondon and enaction, if we do, we must be ready to grant we are machines too, only put together differently.

\footnotetext{
13 Transgenic experiments in Rhesus monkeys with copies of MCPH1, a key human brain development gene, show slowed down brain development, retention of juvenile features, and improvement in working memory and reaction times (Shi and $\mathrm{Su} 2019$ ).

${ }^{14}$ The question can be properly raised provided we have a working conception of bodies. Here we are interested in spelling out what the idea of human bodies as involving entangled modes of becoming entails for the question of artificial bodies. Other frameworks may provide a different answer to this question, only that it may not be quite the same question if the notion of human bodies is different.
} 
Deckard's increasing self-doubt and growing feelings for Rachel are the threads that lead him to conclude that replicants are not like any other machine despite the moral burden this implies for someone in his line of work. Might it be the case that no technical object is like the abstract machines of dualistic, either-or epistemology? That value and fact are precisely abstracted modes that are not easily separable in concrete practice, a fortiori in all technological, i.e., transformative, practice?

The question is whether our account of human becoming in some ways prevents us from conceiving the possibility of replicants (in some version). A nondualistic epistemology, on the one hand, cannot see any fundamental difference between a born and bred self-sustaining body and one put together artificially, provided that what is put together indeed amounts to a concrete body satisfying the various operational and existential conditions described earlier. On the other hand, human becoming foregrounds our bodies' path-dependence, variability, and idiosyncrasies. They are open products of history. Is it conceivable that this existential and constitutive aspect of human becoming could also be artificially replicated? The premise in the film is that implanted memories suffice for replicants to think themselves human. Are such implants a sufficient replacement for having lived through a personal history?

There is a sense in which the answer to this question is an abstract yes, at least in principle. The abstract thinker will contend that if the whole universe were created 5 mins ago exactly in the same state as it actually was 5 mins ago, we would never be able to tell the difference. The same if we succeed in creating an artificial human body with implanted memories. This seems self-evident and repeats the first point above that if we could artificially put together real, concrete processes of self-production and selfdistinction, they would thereby be a real body. However, since advances in understanding have a tendency to hide behind walls of self-evidence, perhaps we should turn the critical evaluation of common sense into a handy epistemic habit.

Again, if concrete lived experience didn't count for much, then perhaps all we need for a body to be the product of history is to simulate as best we can the bodily (or brain) traces of putative historical experiences; create the traces of history even if they are not produced by living through history. Assuming this were possible, how would we proceed? The premise seems to be that an intervention at the level of brain patterns would suffice. But if the enactive approach is correct, the mind is not in the head but in the continuous activity of bodies in action. These activities do not only leave traces in (many) brains but practically everywhere. In my body and yours, in my surroundings, my shoes, my desk, my digital pursuits, and so on. The film partially acknowledges this through the device of fake personal photos. But these are props, reaffirmations of what the implanted subject already knows.

The plausibility of this story (memories as implants with some external supports) in the enactive universe might still be salvaged precisely because from this perspective memories are active reconstructions. Flawed raw materials might still enable "real" remembering since in fact memories are always partial and distorted anyway. Enaction is naturally compatible with active approaches to remembering going back to Frederic C. Bartlett (1932) (see Wagoner 2017). It is also compatible with the notion that the activity of remembering is socially situated (Halbwachs 1950; see work on collaborative remembering in long term couples, Harris et al. 2014), enabled by social patterns, places, rituals, modes of dressing, etc. (Connerton 1989). So, provided enough coherence can be found between neural interventions, environmental props, and the 
attitudes of others, it seems possible that a real experience of embodied recall might occur, more or less convincingly depending on circumstances. ${ }^{15}$ History might therefore be effectively "started" at an advanced point as if prior trajectories had been lived through for real

But this is not the arrival point of this line of thinking. Maybe it will not be quite enough to rely on the active capabilities for biographical reconstruction based on neural or other kinds of traces if we conceive these traces, as they do in the film, as mere records. We must reconsider the notion of traces not only in terms of the wider set of locations where they might be found. We must also question the assumed passivity of this notion: the idea of traces as records such that all they can do is either be read or degrade. Here enter considerations of materiality that put the hylomorphism of this view into question. Active matter also bears traces in how it changes, in how it moves and flows between different conditions of metastability and potentiality, bodies show traces in styles of action, in dispositions evoked by environmental configurations, in voice inflections, forms of speech and gestures, patterns of relating and patterns of thinking that we have no reason to presume are "recorded" or "represented" anywhere before the moment they are enacted. Remembering something painful evokes activities in a body that was once in pain. Bodies are historical not because they are "in the past" but because they are part of the advancing process of history here and now. Not only is memory an active achievement of human bodies, we are literally active embodiments of history. As such our own personal history is not a record to be read by an abstract interpreter, but the way our bodies always already engage and braid themselves with the larger flows of human and world history.

These dynamic differences do not have specific locations, records that may be tampered with, they are instead the result of relational and internal changes at the level of whole bodies-in-the-world. They span loose circumstantial couplings across all scales, from neural firing to lifetime development. Short of magic, there is no conceivable technological route to putting a human body together other than allowing it to become a human body.

In this view, replicants lose plausibility. It is hard to imagine Roy Batty's wisdom in the face of death (his "tears in the rain" speech) being spoken by what is essentially a hyperdeveloped 4-year old (the approximate lifespan of a replicant), no matter how heart-wrenching and deeply scarring the experiences of witnessing "attack ships on fire off the shoulder of Orion" might be.

So, are artificial bodies conceivable in the enactive approach? The answer is yes, they are. Whether they can be persons is an open question. Assuming it is possible to set in motion a self-individuating body, with interiority, capable of caring and sensemaking, a real agent in the enactive sense, what remains implausible is the idea that a full real bodily history can be faked. A body is a complex set of entangled identities, metabolic, sensorimotor, interpersonal, social, linguistic, etc. (Di Paolo et al. 2018). There is no reason to think we could not replicate these processes of self-production and self-distinction artificially. It might be even possible to have autonomous artificial

\footnotetext{
$\overline{15}$ This plausibility is enhanced in the movie sequel (Blade Runner 2049, directed by Denis Villeneuve, 2017) where we get a glimpse at the process of manufacture of memories and how in itself involves a special attention to history, to the point that implanted memories can sometimes even be directly derived from real ones. But they still seem to function as a record of history.
} 
bodies whose self-individuation starts at the level of sensorimotor agency bypassing the need for an organismic level of individuation as suggested by Di Paolo et al. (2017). This may work convincingly in the case of some artificial animals. But this conceivability does not immediately guarantee that artificial bodies would resemble human persons who have lived through history. This is unlikely to happen until they themselves have lived through history. And their history will be peculiar, to say the least.

This is a general consequence of the perspective of human bodies as open, unfinished, and perpetually becoming that emerges from our present analysis. More specifically, consider the question of whether artificial bodies would be able to participate in language. It might seem trivial, given the advances in natural language processing, that this is merely a technical problem, one to be resolved algorithmically. This is definitely not the case. Machines that understand spoken commands or can engage in simple linguistic exchanges only simulate language, and the simulation can be at once useful and uncanny. But to be a linguistic body is to participate in a series of multiply organized engagements that allow us to navigate uncertainties in dialogues, to mutually construct meaning on the fly, switch genres of participation adaptively, and build novel accents and images and ideas together with others. It is to be able to participate in and contribute to the braided history of human communities. Enaction proposes that we become linguistic by actual participation in languaging, via full linguistic engagement with the flow of language since birth, and even before. The skills of language use are not merely added to sensorimotor and organic skills, they continuously redefine them. Hence, bodies can only become linguistic through real participation in linguistic communities. No shortcuts.

The difference real history makes becomes clearer when we look at it from a Simondonian perspective of concretization. There is an innumerable set of ways in which bodies become historically attuned to their associated milieu, and in turn change it. Fluctuations get amplified, random changes locked-in. Being a body open to sources of potentiality becomes a path-dependent endeavor that achieves transindividual determination in real communities. There is no bypassing of history.

If we make artificial creatures at some point in the future (real creatures, precariously autonomous in the enactive sense, and thereby proper agents and sense-makers), they will require technologies that are at odds with current engineering approaches, which are based on compartmentalization and relatively isolated systemic hierarchies. Historical concretization is precisely the "ambiguation" of barriers and compartments. ${ }^{16}$ However this first step may be achieved, the resulting creature will in addition need to spend time living in the real human world, forging relations, walking paths, altering the environment, making mistakes, being injured, and learning to participate, resist, forgive, and love to eventually count as a person.

On a final note, we may wonder if it is indeed human becoming that we should prescribe for replicants. Perhaps we are being rash in favoring the possibilities of recognition over those of estrangement. A nonhuman path to becoming could serve as a way of healthily rethinking personhood through radical variation but, according to

\footnotetext{
${ }^{16}$ On a hopeful note, according to Simondon (1958), concretization is a tendency in the mode of existence of technical objects as they develop through concrete usage. Most modern digital design principles, however, actively discourage or build barriers to prevent concretization where functions are fluid and affected by materiality.
} 
the foregoing, if there is to be such a path then belonging to linguistic communities and participating in history still cannot be avoided. Like in the human case, there cannot be specifically replicant becomings without replicant communities. ${ }^{17}$

The conclusion to be highlighted here: the bodies of persons, human or otherwise, must engage in forms of actual historical, open becoming. This is what makes them the bodies of persons. This is as important a constituent of the enactive idea of bodies, as are the concepts of autonomy, individuation, agency, and sense-making. Concrete becoming does not reside in a particular anatomy, a particular set of skills, not in even in high intelligence, all of which can be imitated in hollow ways. But in the capacity of bodies to engage in living history-making with other bodies.

Acknowledgments Thanks to Hanne De Jaegher, Elena Cuffari and two anonymous reviewers for their helpful comments on earlier versions of this text.

Open Access This article is licensed under a Creative Commons Attribution 4.0 International License, which permits use, sharing, adaptation, distribution and reproduction in any medium or format, as long as you give appropriate credit to the original author(s) and the source, provide a link to the Creative Commons licence, and indicate if changes were made. The images or other third party material in this article are included in the article's Creative Commons licence, unless indicated otherwise in a credit line to the material. If material is not included in the article's Creative Commons licence and your intended use is not permitted by statutory regulation or exceeds the permitted use, you will need to obtain permission directly from the copyright holder. To view a copy of this licence, visit http://creativecommons.org/licenses/by/4.0/.

\section{References}

Adolph, K. E., \& Hoch, J. E. (2019). Motor development: Embodied, embedded, enculturated, and enabling. Annual Review of Psychology, 70, 141-164.

Allport, G. W. (1955). Becoming: Basic considerations for a psychology of personality. New Haven: Yale University Press.

Au, W. (2018). A Marxist education: Learning to change the world. Chicago: Haymarket Books.

Balibar, É. (2018). Philosophies of the transindividual: Spinoza, Marx, Freud. Australasian Philosophical Review, 2(1), 5-25.

Bakhtin, M. M. (1984). Problems of Dostoevsky's Poetics (C. Emerson, Trans.). Minneapolis: University of Minnesota Press.

Bartlett, F. C. (1932). Remembering: A study in experimental and social psychology. Cambridge: Cambridge University Press.

Bourdieu, P. (1990). The logic of practice. Stanford: Stanford University Press.

Césaire, A. (1950/1972). Discourse on colonialism (Trans. J. Pinkham). This version published by: New York: Monthly Review Press.

Charlesworth, S. J. (2000). A phenomenology of working-class experience. Cambridge: Cambridge University Press.

Combes, M. (2013). Gilbert Simondon and the philosophy of the transindividual (trans. T. LaMarre) Cambridge: MIT Press.

Connerton, P. (1989). How societies remember. Cambridge: Cambridge University Press.

Cuffari, E. (2011). Habits of transformation. Hypatia, 26(3), 535-553.

Cuffari, E., Di Paolo, E. A., \& De Jaegher, H. (2015). From participatory sense-making to language: There and back again. Phenomenology and the Cognitive Sciences, 14(4), 1089-1025.

\footnotetext{
${ }^{17}$ The bonds of alliance between the rebel replicants in Blade Runner could be a sign in this direction, particularly since their mutual commitment and solidarity seem slightly unrecognizable from the perspective of individualistic consumerist societies, a fact highlighted by the social isolation of the human characters in the film.
} 
De Jaegher, H. (2019). Loving and knowing: Reflections for an engaged epistemology. Phenomenology and the Cognitive Sciences, 1-24. https://doi.org/10.1007/s11097-019-09634-5.

De Jaegher, H., \& Di Paolo, E. A. (2007). Participatory sense-making: An enactive approach to social cognition. Phenomenology and the Cognitive Sciences, 6, 485-507.

De Jaegher, H., Di Paolo, E. A., \& Gallagher, S. (2010). Can social interaction constitute social cognition? Trends in Cognitive Sciences, 14, 441-447.

della Mirandola, G. P. (1948). Oration on the dignity of man (trans. E. Livermore Forbes). In E. Cassirer, P. O. Kristeller, \& J. H. Randall Jr. (Eds.), The renaissance philosophy of man (pp. 223-254). Chicago: The University of Chicago Press.

Dewey, J. (1922/1988). Human nature and conduct. Carbondale: Southern Illinois University Press.

Di Paolo, E. A. (2005). Autopoiesis, adaptivity, teleology, agency. Phenomenology and the Cognitive Sciences, 4, 429-452.

Di Paolo, E. (2015). Interactive time-travel: On the intersubjective retro-modulation of intentions. Journal of Consciousness Studies, 22(1-2), 49-74.

Di Paolo, E. A. (2018). The enactive conception of life. In A. Newen, S. Gallagher, \& L. de Bruin (Eds.), The Oxford handbook of cognition: Embodied, embedded, enactive and extended, (pp 71-94). Oxford University Press.

Di Paolo, E. A., \& De Jaegher, H. (2012). The interactive brain hypothesis. Frontiers in Human Neuroscience, 6, 163. https://doi.org/10.3389/fnhum.2012.00163.

Di Paolo, E. A., Buhrmann, T., \& Barandiaran, X. E. (2017). Sensorimotor life: An enactive proposal. Oxford: Oxford University Press.

Di Paolo, E. A., Cuffari, E. C., \& De Jaegher, H. (2018). Linguistic bodies: The continuity between life and language. Cambridge: MIT Press.

Di Paolo, E. A. \& Thompson, E. (2014). The enactive approach, in L. Shapiro, ed., The Routledge Handbook of Embodied Cognition, London: Routledge Press. pp. 68-78.

DiFrisco, J. (2014). Hylomorphism and the metabolic closure conception of life. Acta Biotheoretica, 62, 499525 .

Du Bois, W. E. B. (1903). The souls of black folk. Chicago: A.C. McClurg \& Co..

Du Bois, J. W. (2014). Towards a dialogic syntax. Cognitive Linguistics, 25(3), 359-410.

Duhem, L. (2012). Apeiron et physis. Simondon transducteur des présocratiques. In: J-H. Barthélémy (ed.) Cahiers Simondon. Numéro 4. Paris: L'Harmattan.

Fanon, F. (1952/1986). Black skins, white masks (G. L. Markmann, Trans.). London: Pluto Press.

Fanon, F. (1963/2004). The wretched of the earth. (R. Philcox, Trans.). New York: Grove Press.

Freire, P. (1974/2013). Education for critical consciousness. London: Bloomsbury.

Freire, P. (1996). Pedagogy of the oppressed (M. Bergman Ramos, Trans.). London: Penguin Books.

Fuchs, T., \& De Jaegher, H. (2009). Enactive intersubjectivity: Participatory sense- making and mutual incorporation. Phenomenology and the Cognitive Sciences, 8(4), 465-486.

Goodwin, C. (2018). Co-operative action. Cambridge: Cambridge University Press.

Halbwachs, M. (1950). La mémoire collective. Paris: Albin Michel.

Harris, C. B., Barnier, A. J., Sutton, J., \& Keil, P. G. (2014). Couples as socially distributed cognitive systems: Remembering in everyday social and material contexts. Memory Studies, 7(3), 285-297.

Heidegger, M. (2001). Phenomenological interpretations of Aristotle. Initiation into phenomenological research. (R. Rojcewicz, Trans.) Bloomington: Indiana University Press.

hooks, b. (1994). Teaching to transgress: Education as the practice of freedom. New York: Routledge.

Kimmerer, R. W. (2013). Braiding Sweetgrass: Indigenous wisdom, scientific knowledge and the teachings of plants. Minneapolis: Milkweed Editions.

Korsgaard, C. (2009). Self-constitution: Agency, identity, and integrity. Oxford: Oxford University Press.

Landecker, H., \& Panofsky, A. (2013). From social structure to gene regulation, and back: A critical introduction to environmental epigenetics for sociology. Annual Review of Sociology, 39, 333-357.

Landes, D. (2017). Language and development: Paradoxical trajectories in Merleau-Ponty, Simondon, and Bergson. Phenomenology and the Cognitive Sciences, 16(4), 597-607.

Langer, S. K. (1967). Mind: An essay on human feeling (Vol. 1). Baltimore: The Johns Hopkins Press.

Latash, M. L. (2008). Synergy. Oxford: Oxford University Press.

Ledwith, M. (2016). Community development in action: Putting Freire into practice. Bristol: Policy Press, University of Bristol.

Lugones, M. (2003). Pilgrimages/peregrinajes: Theorizing coalition against multiple oppressions. Lanham: Rowman and Littlefield.

Maclaren, K. (2017). Merleau-Ponty on human development and the retrospective realization of potential. Phenomenology and the Cognitive Sciences, 16(4), 609-621. 
Marx, K. (1970). A contribution to the critique of political economy (S. W. Ryazanskaya, Trans., M. Dobb, Ed). New York: International Publishers.

Maturana, H., and Varela, F. J. (1980). Autopoiesis and Cognition: The Realization of the Living. Dordrecht, The Netherlands: D. Reidel.

Marx, K. (1973). Grundrisse: Foundations of the critique of political economy (M. Nicolaus, Trans. London: Penguin.

McManus, D. (2013). The provocation to look and see: Appropriation, recollection and formal indication. In S. Reynolds, D. Egan, \& A. Wendland (Eds.), Wittgenstein and Heidegger (pp. 50-65). London: Routledge.

Mead, G. H. (1932). The physical thing. In: G. H. Mead, The philosophy of the present. A. E. Murphy (ed.) (pp. 119-39). LaSalle: Open Court.

Merleau-Ponty, M. (1942/1963). The structure of behavior (A. L. Fisher, Trans.). Boston: Beacon Press.

Merleau-Ponty, M. (1945/2012). Phenomenology of perception. 2nd ed. D. Landes (trans.). London: Routledge.

Mol, A., \& Law, J. (2004). Embodied action, enacted bodies: The example of hypo-glycaemia. Body \& Society, $10(2-3), 43-62$.

Montagu, A. (1989). Growing young (2nd ed.). New York: Bergin and Garvey.

Overton, W. F. (2015). Processes, relations, and relational-developmental-systems. In W. F. Overton, P. C. M. Molenaar, \& R. M. Lerner (Eds.), Handbook of child psychology and developmental science: Theory and method (pp. 9-62). Hoboken: John Wiley \& Sons.

Read, J. (2015). The politics of transindividuality. Chicago: Haymarket Books.

Scott, R. (director) (1982). Blade Runner, Warner Bros. Home Entertainment, USA.

Shaviro, S. (2015). Discognition. London: Repeater Books.

Shi, L., \& Su, B. (2019). A transgenic monkey model for the study of human brain evolution. Zoological Research, 40(3), 236-238.

Simondon, G. (1958/2017). On the mode of existence of technical objects (C. Malaspina \& J. Rogove, Trans.). Minneapolis: Univocal.

Simondon, G. (2005). L'Individuation à la lumière des notions de forme et d'information. Grenoble: Millon.

Simondon, G. (2009). The position of the problem of ontogenesis. Parrhesia, 7, 4-16.

Simondon, G. (2016). Pour une notion de situation dialectique (1960). In Simondon, G., Sur la Philosophie (1950-1980). Paris: PUF. (pp. 101-105).

Stetsenko, A. (2017). The transformative mind. Expanding Vygotsky's approach to development and education. Cambridge: Cambridge University Press.

Sullivan, S. (2001). Living across and through skins: Transactional bodies, pragmatism, and feminism. Carbondale: Indiana University Press.

Thompson, E. (2007). Mind in life: Biology, phenomenology and the sciences of mind. Cambridge: Harvard University Press.

Thompson, E., \& Varela, F. J. (2001). Radical embodiment: Neural dynamics and consciousness. Trends in Cognitive Sciences, 5, 418-425.

Turvey, M. T. (2007). Action and perception at the level of synergies. Human Movement Science, 26, 657697.

Varela, F. J. (1997). Patterns of life: Intertwining identity and cognition. Brain and Cognition, 34, $72-87$.

Villeneuve, D. (director) (2017). Blade Runner 2049, Warner Bros. Home Entertainment, USA.

Virno, P. (2015). When the word becomes flesh: Language and human nature. Los Angeles: Semiotext(e).

Voloshinov, V. N. (1929/1973). Marxism and the philosophy of language (Trans. L. Matejka \& I. R. Titunik). Cambridge: Harvard University Press.

Wagoner, B. (2017). The constructive mind: Bartlett's psychology in reconstruction. Cambridge: Cambridge University Press.

Weber, A., \& Varela, F. (2002). Life after Kant: Natural purposes and the autopoietic foundations of biological individuality. Phenomenology and the Cognitive Sciences, 1, 97-125.

Witherington, D. C., Overton, W. F., Lickliter, R., Marshall, P. J., \& Narvaez, D. (2018). Metatheory and the primacy of conceptual analysis in developmental science. Human Development, 61, 181-198.

Young, I. M. (2005). On female body experience: "Throwing like a girl" and other essays. Oxford: Oxford University Press.

Publisher's note Springer Nature remains neutral with regard to jurisdictional claims in published maps and institutional affiliations. 